\title{
Interferon Lambda: A New Sword in Cancer Immunotherapy
}

\author{
Ahmed Lasfar, ${ }^{1}$ Walid Abushahba, ${ }^{2}$ Murugabaskar Balan, ${ }^{2}$ and Karine A. Cohen-Solal ${ }^{2}$ \\ ${ }^{1}$ Department of Biochemistry and Molecular Biology, University of Medicine and Dentistry of New Jersey-New Jersey Medical School, \\ University Hospital Cancer Center, 205 South Orange Avenue, Newark, NJ 07103, USA \\ ${ }^{2}$ Department of Medicine, Division of Medical Oncology, UMDNJ-Robert Wood Johnson Medical School, \\ The Cancer Institute of New Jersey, 195 Little Albany Street, New Brunswick, NJ 08903, USA
}

Correspondence should be addressed to Ahmed Lasfar, lasfarah@gmail.com

Received 1 July 2011; Accepted 16 September 2011

Academic Editor: Graham Ogg

Copyright (c) 2011 Ahmed Lasfar et al. This is an open access article distributed under the Creative Commons Attribution License, which permits unrestricted use, distribution, and reproduction in any medium, provided the original work is properly cited.

The discovery of the interferon-lambda (IFN- $\lambda$ ) family has considerably contributed to our understanding of the role of interferon not only in viral infections but also in cancer. IFN- $\lambda$ proteins belong to the new type III IFN group. Type III IFN is structurally similar to type II IFN (IFN- $\gamma$ ) but functionally identical to type I IFN (IFN- $\alpha / \beta)$. However, in contrast to type I or type II IFNs, the response to type III IFN is highly cell-type specific. Only epithelial-like cells and to a lesser extent some immune cells respond to IFN- $\lambda$. This particular pattern of response is controlled by the differential expression of the IFN- $\lambda$ receptor, which, in contrast to IFN- $\alpha$, should result in limited side effects in patients. Recently, we and other groups have shown in several animal models a potent antitumor role of IFN- $\lambda$ that will open a new challenging era for the current IFN therapy.

\section{Introduction}

Despite the early discovery of interferon (IFN) in 1957, IFN lambdas were just identified during the recent years and classified as a new group, type III IFN. In human, 3 distinct proteins called IFN- $\lambda 1$, IFN- $\lambda 2$, and IFN- $\lambda 3$ have been identified $[1,2]$. They are also named interleukin-29 (IL29), IL-28A, and IL-28B, respectively [3]. The members of this new IFN family were found to interact through unique receptors that are distinct from type I $(\operatorname{IFN}-\alpha / \beta)$ and type II $($ IFN- $\gamma$ ) IFN receptors. The receptor for type III IFN is composed of the unique IFN- $\lambda \mathrm{R} 1$ chain also called IL28AR and the IL-10R2 chain, which is shared with IL-10, IL-22, and IL-26 receptor complexes. Although type III IFNs bind to a specific receptor, the downstream signaling is similar to that induced by type I IFNs. Both type I and type III IFNs stimulate common signaling pathways, consisting of the activation of Jak1 and Tyk2 kinases and leading to the activation of IFN-stimulated gene factor 3 (ISGF3) transcription complex. ISGF3 is composed of STAT1 and STAT2 and the interferon regulatory factor IRF9 (ISGF3- $\gamma$ or p48) (Figure 1). Although there are three genes encoding highly homologous but distinct human IFN- $\lambda$ proteins (IFN$\lambda 1$, IFN- $\lambda 2$, and IFN- $\lambda 3$ ), our search of the mouse genome revealed the existence of only two genes, representing mouse IFN- $\lambda 2$ and IFN- $\lambda 3$ gene orthologues, located in chromosome 7 and encoding intact proteins. The mouse IFN- $\lambda 1$ gene orthologue is a pseudogene containing some variations in addition to a stop codon in the first exon and does not code for an active protein [4]. We have cloned the mouse IFN$\lambda s$ (mIFN- $\lambda 2$ and $\mathrm{mIFN}-\lambda 3$ ) and IFN- $\lambda$ receptor (mIFN$\lambda \mathrm{R} 1$ ) orthologues and found them to be quite similar to their human counterparts. Experiments showed that similar to their human counterparts, mIFN- $\lambda 2$ and mIFN- $\lambda 3$ signal through the IFN- $\lambda$ receptor complex, activate ISGF3, and are capable of inducing antiviral protection and MHC class I antigen expression in several cell types. The results showed that murine type III IFNs (IFN- $\lambda s$ ) engage a unique receptor complex, composed of IFN- $\lambda$ R1 and IL-10R2 subunits, to induce signaling and biological activities similar to those of type I IFNs. Interestingly, in contrast to type I and type II IFNs, type III IFNs demonstrate less species specificity.

\section{Biological Properties of IFN- $\lambda$}

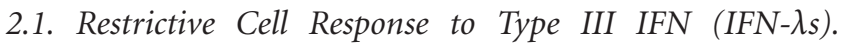
Although type I and type III induced similar cell signaling, 


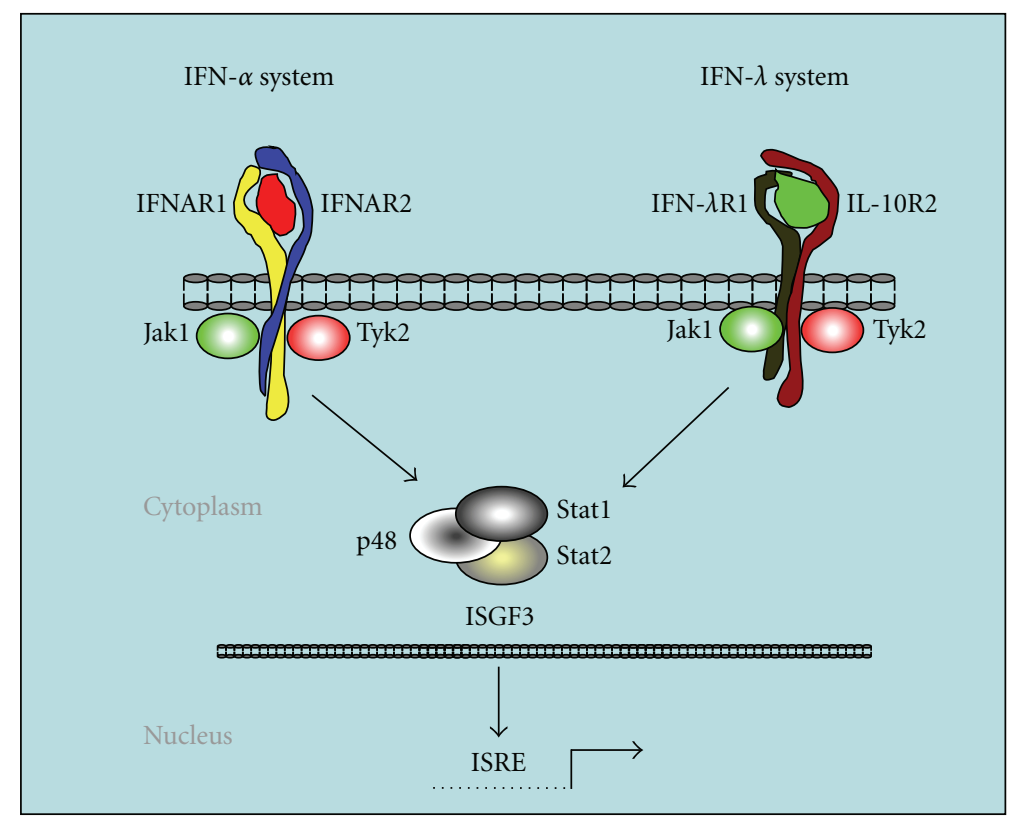

FIGURE 1: IFN- $\alpha$ and IFN- $\lambda$ receptor systems and cell signaling. IFN- $\alpha$ and IFN- $\lambda$ interact with distinct receptors, but the downstream signaling is similar. IFN- $\alpha$ interacts with receptors composed of IFNAR1 and IFNAR2, and IFN- $\lambda$ interacts with a receptor composed of a specific chain, IFN- $\lambda$ R1, and IL-10R2, a shared subunit with IL-10, IL-22, and IL-26. Both IFNs lead to the activation of the Jak kinases (Jak1 and Tyk2) and the formation of the transcription-complex-designated IFN-stimulated gene factor 3 (ISGF3), which includes p48, Stat1, and Stat2. ISGF3 complex binds to the IFN-stimulated response element (ISRE) and induces gene transcription.

the intensity of cell signaling as measured by STAT1 activation appeared to be significantly lower for type III IFNs [4]. In comparison with type I IFN, only restricted cell types respond to type III IFN (Figure 2). Interestingly, we did not find a strict correlation between the intensity of cell signaling induced by IFN- $\lambda$ and the level of biological activity. For example, in B16 melanoma cells, although IFN $-\lambda$ induced a very weak STAT1 activation in comparison with IFN- $\alpha$, we observed a robust stimulation of MHC class I expression at the cell surface, indicating the potential contribution of cellspecific modulators of the IFN- $\lambda$ activity.

Antiviral studies performed in vitro and in vivo have shown that both IFN- $\alpha$ and IFN- $\lambda$ contribute to the overall host antiviral defense system $[2,3,5-8]$. It has been demonstrated that IFN- $\lambda$ induces antiviral activity against VSV (vesicular stomatitis virus) and EMCV (encephalomyocarditis) in many human cell lines $[2,3,9,10]$. However, by using different mouse models of viral infection, Ank et al. demonstrated that IFN- $\lambda$ was effective against DNA virus, simplex virus 2 HSV2 but not RNA viruses such as EMCV and lymphocytic choriomeningitis virus LCMV [6]. Several other studies demonstrated that type III IFNs can also inhibit replication of hepatitis $\mathrm{C}$ virus (HCV) and hepatitis B virus (HBV) in vitro [10-14]. These studies were important since they underlined the fact that IFN $-\lambda$ could be used as an alternative to IFN- $\alpha$ for HCV patients who are resistant to IFN- $\alpha$ treatment. It has been reported that IFN- $\lambda$ has the ability to inhibit human immunodeficiency virus type 1 (HIV-1) infection of blood monocyte-derived macrophages that expressed IFN- $\lambda$ receptors [15] and the herpes simplex virus type 1 (HSV1) infection of human astrocytes and neurons [16]. However, in most other cases, the antiviral potency of IFN- $\lambda$ against several viruses seems to be lower than that of IFN- $\alpha[2,3,8,9,13,17]$. In addition, IFN- $\lambda$ and IFN- $\alpha$ may induce distinct signal transduction and gene regulation kinetics $[13,18]$.

Moreover, type I IFN- $\alpha$ activates a plethora of innate and adaptive immune mechanisms that help eliminate tumors and viral infections. IFN- $\alpha$ immunoregulatory functions include major histocompatibility complex (MHC) class I expression in normal and tumor cells, activation of NK cells, dendritic cells (DCs), and macrophages, resulting in the promotion of adaptive immune responses against tumors and virally infected cells $[19,20]$. The role of IFN- $\lambda$ in the immune system is currently being investigated by several groups. So far, data suggests that IFN- $\lambda$ exerts immunomodulatory effects that overlap those of type I IFN. It has been recently demonstrated that human IFN- $\lambda 1$ (IL-29) modulates the human plasmacytoid DCs function and cytokine response $[21,22]$. IFN- $\lambda 1$ treatment of whole peripheral blood mononuclear cells (PBMCs) upregulated the expression of IL-6, IL-8, and IL-10 but not IL-1 or TNF. This IFN- $\lambda$-induced cytokine production was inhibited by IL-10. By examination of purified cell populations, it was also shown that IFN- $\lambda 1$ activated monocytes, rather than lymphocytes, resulting in the secretion of the above panel of cytokines, suggesting that IFN- $\lambda 1$ may be an important activator of innate immune responses particularly at the site of viral infections [21]. IFN- $\lambda 1$ was also shown to possess immunoregulatory functions on $\mathrm{T}$ helper 2 (Th2) responses by markedly inhibiting IL-13. However, only moderate effect was observed on IL-4 and IL-15, the 


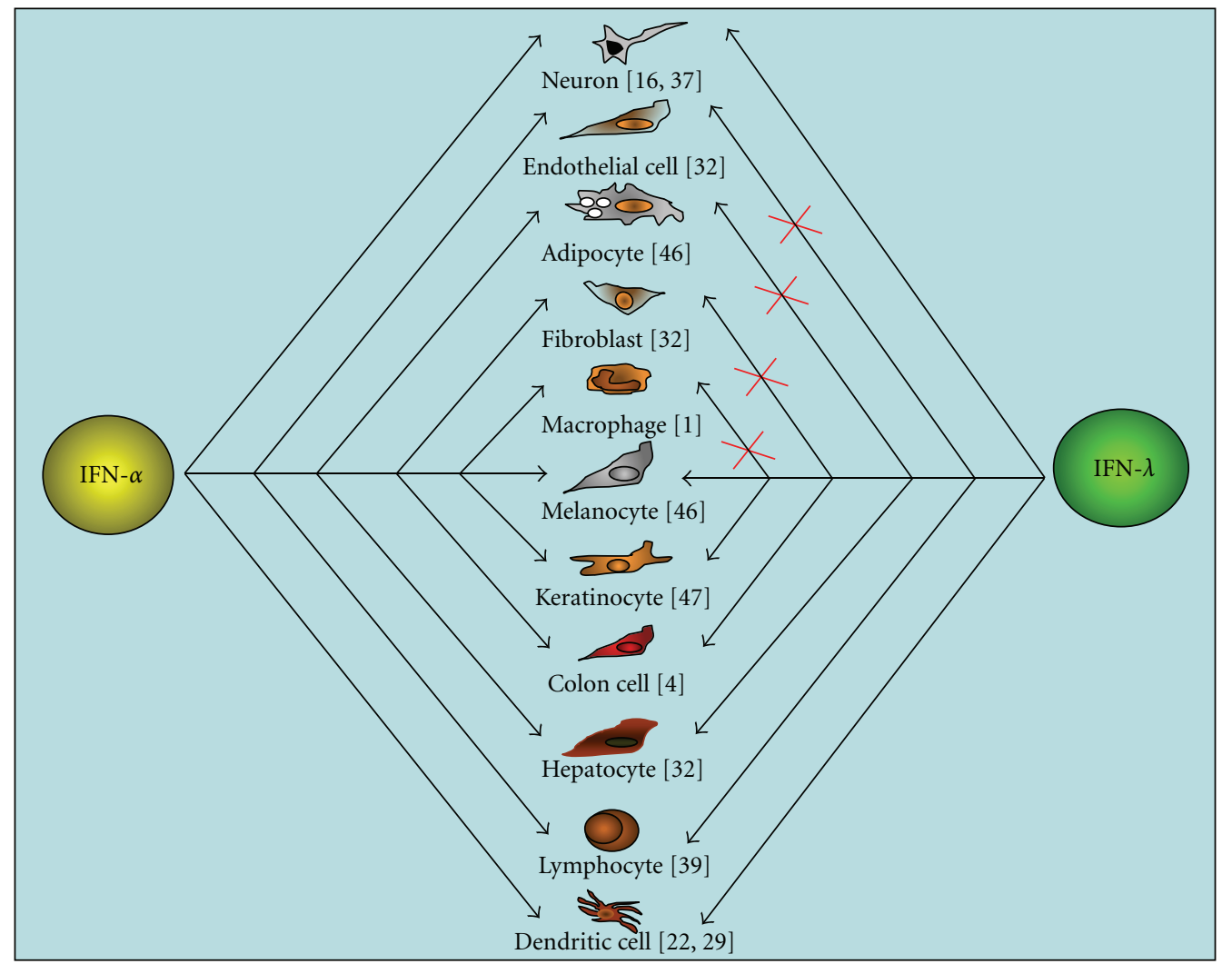

Figure 2: Cellular targets for type I and type III IFNs. Response to IFN- $\alpha$ and IFN- $\lambda$ in cells from different origins in human. The IFN response was assessed by measuring the IFN-induced cell signaling (Stat activation) and cell activity (MHC class I antigen stimulation). In contrast to IFN- $\alpha$, only restricted cells respond to IFN- $\lambda$, including epithelial-like cells, forming the major organs of the body.

other important cytokines in the Th2 response [23-25]. This immunoregulatory function was enhanced through the expression of IFN- $\lambda \mathrm{R} 1$ on $\mathrm{CD} 4^{+} \mathrm{T}$ cells $[23]$. These findings correlate with data suggesting that IFN- $\lambda$ may have an immunoprotective role against asthma, the allergy disease caused by an exaggerated Th2 response $[9,26,27]$.

Similar to IFN- $\alpha$, IFN- $\lambda$ produced by DCs, in response to toll-like receptor (TLR) stimulation, was found to have specific effects on DC differentiation and maturation [28], which include only partial maturation of DCs, upregulation of MHC class I and II molecules, and no induction of costimulatory molecules $[9,29]$. During their differentiation from monocytes, DCs acquire IFN $-\lambda$ responsiveness through the expression of IFN- $\lambda$ R1. Interestingly, DCs treated with IFN- $\lambda$ promoted the generation of tolerogenic DCs and the IL-2-dependent proliferation of Foxp3-expressing $\mathrm{CD} 4^{+} \mathrm{CD} 25^{+}$regulatory $\mathrm{T}$ cells (Tregs) [29]. More recently, Morrow et al. have demonstrated, through DNA vaccination with plasmids encoding IFN- $\lambda 3$ (IL-28B) and IL-12, that IFN- $\lambda 3$, just like IL-12, is able to enhance adaptive immunity. However, in contrast to IL-12, IFN- $\lambda 3$ reduces regulatory Tcell populations. They also showed that unlike IL-12, IFN- $\lambda 3$ is able to increase the percentage of splenic $\mathrm{CD} 8^{+} \mathrm{T}$ cells in vaccinated animals and that IFN $-\lambda 3$ can completely protect mice from death following a lethal influenza challenge [30].
These studies altogether highlight the strong candidacy of IFN- $\lambda$ as a potential novel immunotherapeutic agent.

In addition to antiviral and immunomodulatory activities, type I IFNs demonstrate antiproliferative activities in most cell lines, while this activity seems to be restricted with IFN- $\lambda$ s $[9,17]$. Type I IFNs have been shown to induce apoptosis in tumor cells, yet the molecular mechanisms mediating cell death in response to these IFNs remain to be fully explained. By binding to their corresponding cellular receptor complexes, IFNs induce a quick and potent signaling which leads to the expression of more than 300 IFN-stimulated genes (ISGs) [13, 31, 32]. Many ISGs encode proteins that have been implicated in apoptosis $[33,34]$. Unlike IFN- $\alpha$, IFN- $\lambda$ s do not inhibit the proliferation of several cell lines including the Daudi cells (a B-lymphoblastoid cell line from Burkitt's lymphoma), which strongly respond to type I IFNs in an antiproliferative assay $[2,3,10,17]$. However, it was demonstrated that IFN- $\lambda$ s do inhibit the proliferation of few tumor cell lines, such as the LN319 human gliobastoma cell line [17] and of cells constitutively expressing high levels of IFN- $\lambda$ R1 [35]. The antiproliferative effects of IFN- $\lambda$ have been demonstrated in various tumor cell lines that express ectopic or endogenous IFN- $\lambda$ receptors $[17,36,37]$. Therefore, the ability of IFN- $\lambda$ s to induce antiproliferative activity in cells depends on the level of IFN$\lambda \mathrm{R} 1$ expression. 
It has been recently reported that IFN- $\lambda$ signaling in colorectal adenocarcinoma HT29 cells led to caspase activation, externalization of phosphatidylserine (PS), and DNA fragmentation, resulting in subsequent apoptosis [38]. This study provided evidence for the first time that type III IFNs, alone or in combination with other stimuli, have the potential to induce apoptosis. Moreover, another recent study revealed that IFN- $\alpha$ and IFN- $\lambda$ differ in their antiproliferative effects and this was correlated with a difference in the duration of JAK/STAT signaling activity between the two IFNs and prolonged ISG expression upon IFN- $\lambda$ treatment [18]. Using the human keratinocyte HaCaT cell line that expresses receptors for both IFN- $\alpha$ and IFN- $\lambda$, they found that IFN- $\lambda$ induced a more pronounced growth inhibitory effect than IFN- $\alpha$. IFN- $\lambda$ was also more efficient than IFN- $\alpha$ in inducing an antiproliferative effect that overlapped with the activation of apoptosis. Prolonged duration of IFN- $\lambda$ induced STAT activation, and ISG expression could account for the enhanced antiproliferative and proapoptotic effects observed in $\mathrm{HaCaT}$ cells, effects not seen upon treatment with high doses of IFN- $\alpha$ [18]. Interestingly, a study has shown that IFN- $\lambda$ can induce the growth of human multiplemyeloma cells and antagonize the dexamethasone-induced cell death in these cells [39]. IFN- $\lambda$-mediated cell growth of multiple myeloma cells was MAPK dependent [39]. High level of IFN- $\lambda$ was found in the malignant bone marrow microenvironment, implying that IFN- $\lambda$ may play a direct role in multiple myeloma development.

\subsection{Tissue and Species Specificity of Type III IFN (IFN- $\lambda$ ).} By using a plasmid electrotransfer approach, Sommereyns and coworkers reported a differential response to IFN- $\lambda$ in mice, with a very low response to IFN- $\lambda$ for the liver, central nervous system, and spleen. However, a high response to IFN- $\lambda$ was observed in the stomach, intestine, heart, kidney, and lung [40]. The IFN- $\lambda$ response was restricted to epithelial cells and correlated with the expression of IFN- $\lambda \mathrm{R}$ (IL28Ralpha). Paradoxically in mice, in spite of the epithelial nature of the hepatocytes, the liver expressed low levels of IL-28Ralpha and responded poorly to IFN- $\lambda[8,40]$. However, a significant response to IFN- $\lambda$ was reported in human hepatocytes $[13,32]$, suggesting the existence of some variations in the response to IFN- $\lambda$ between mice and humans, at least in the liver. Although the main IFN- $\lambda$ targets are the epithelial cells, the presence of potential tissuespecific factors may modulate the IFN- $\lambda$ response through the IFN- $\lambda$ receptors. Recently, it has been shown in mice that in contrast to the hepatocytes, prominent response to IFN$\lambda$ was observed in intestinal epithelial cells. In comparison with IFN $-\alpha$, this response is higher and plays a critical role in protecting the intestinal epithelium from viral infection [41], strongly suggesting the prominent role of IFN- $\lambda$ in organs with mucosal surface at least in mice $[6,42,43]$. In addition to the direct effect of IFN- $\lambda$ on the mucosal epithelium, local immunomodulations can also be promoted [44].

2.3. Distribution of IFN- $\lambda R 1$ and Responsiveness to IFN- $\lambda$. The functional IFN- $\lambda \mathrm{R}$ is formed by two chain proteins,
IFN- $\lambda$ R1 (also called IL-28Ralpha) and IL-10R2. IFN- $\lambda$ R1 is unique for the IFN- $\lambda \mathrm{s}$, and its tissue distribution is highly restricted. In contrast to IFN- $\lambda$ R1, IL-10R2 is shared by IL-10, IL-22 and IL-26 and ubiquitously expressed in all tissues. Unlike IFN- $\alpha$, only few cell types respond to IFN- $\lambda$ (Figure 2). In contrast to the epithelial-like cells, fibroblasts and endothelial cells were completely unresponsive to IFN- $\lambda$ [4]. Although the hematopoeitic system is not the primary target of IFN $-\lambda$, the response of some subpopulations to IFN $-\lambda$ is not excluded. In mice, we found that IFN- $\lambda$ induces STAT1 activation in both plasmacytoid and myeloid dendritic cells [45]. These results are in accordance with those obtained by Mennechet and Uzé [29], who proposed the acquisition of an IFN- $\lambda$ response by monocytes after their differentiation into dendritic cells. Therefore, the response to IFN- $\lambda$ may be controlled by the induction of the IFN$\lambda \mathrm{R} 1$ expression. Different levels of IFN- $\lambda \mathrm{R} 1$ were found in different tissues $[40,43,46]$. The highest levels were found in the gastrointestinal tract and lung. The brain showed the lowest level of receptor expression. The IFN$\lambda \mathrm{R} 1$ expression was also analyzed in different cell types. The expression of cell populations isolated from human skin showed a high expression of IFN- $\lambda$ R1 in keratinocytes and melanocytes. However, dermal fibroblasts, endothelial cells, and subdermal adipocytes did not express significant amounts of IFN- $\lambda$ R1. Significant expression of IFN- $\lambda$ R1 was detected in primary human hepatocytes in comparison with the chondrocytes, isolated from the hyaline cartilage of the knee joint $[46,47]$. Although the expression of IFN- $\lambda$ R1 was significantly high in lymphoid tissues, the IFN- $\lambda$ response was very weak, implying the presence of specific mechanisms in the lymphoid tissues that may inhibit the IFN- $\lambda$ response. For example, IFN- $\lambda \mathrm{R} 1$ levels in B cells are threefold those detected in keratinocytes, which exhibit one of the highest responses to IFN- $\lambda$. Witte et al. proposed the potential role of soluble IFN- $\lambda$ R1, highly released by the immune cells, in this weak response to IFN- $\lambda$ [46].

Although all the IFN- $\lambda$ s interact with the same receptor, IFN- $\lambda \mathrm{R} 1$, the binding characteristics for each ligand are still under investigation. In the future, it will be important to analyze the IFN- $\lambda$ activity in light of the IFN- $\lambda$ binding to the cells and understand particularly the role of IFN$\lambda 3$, which possesses the highest activity as compared with the other IFN- $\lambda$ s $[48,49]$. Analysis of the ligand binding in combination with the activity induced by IFN- $\lambda$ will be also important in understanding the impact of IFN- $\lambda$ in epithelial cells, particularly in comparison with the immune cells expressing IFN- $\lambda \mathrm{R} 1$. Besides several carcinomas, originating from epithelial cells, which respond to IFN- $\lambda$, other tumors not arising from epithelial cells may become more sensitive to IFN- $\lambda$. It was reported that multiple myeloma cells, which originate from B-cell plasmocytes, showed high binding and response to IFN- $\lambda$ [39]. Studying the IFN- $\lambda$ binding in transformed cells versus normal cells may be very helpful for tumor targeting and for the establishment of the optimum dose of IFN- $\lambda$ to be used for the in vivo treatment. IFN- $\lambda$ can also be used as a drug carrier, to specifically target a drug to tumors expressing high IFN- $\lambda$ binding sites. 
2.4. Antiviral Protection in IFN-Type-III-Deficient Mice. The availability of IFN- $\lambda \mathrm{R} 1$ knock-out mice allowed for the investigation of the role of type III IFNs in vivo. By using those mice, Mordstein et al. showed for the first time the contribution of IFN- $\lambda$ in the innate immunity against the influenza virus [8]. Later, they found that IFN- $\lambda$ played an important role in the defense against other pathogens that infect the respiratory tract, such as the respiratory syncitial virus, the metapneumovirus, and the severe acute respiratory syndrome (SARS) coronavirus. However, the lassa fever virus which replicates in the liver, was not affected by the lack of IFN- $\lambda$ R1 [50]. Although this study clearly demonstrated that IFN- $\lambda$ played an important role in protecting the respiratory and gastrointestinal tracts against virus infection, in comparison with type I IFN, the protection provided by type III IFN remains limited. However, in combination, type I and type III may provide a better viral protection. When the response to both type I and type III is deficient, the mice are not able to clear the SARS coronavirus from the intestine as compared with mice in which type I or type III remains functional, implying that IFN- $\lambda$ may strengthen the antiviral activity by acting as a first line of defense for the mucosa $[8,50]$.

2.5. Clinical Use of Type III IFN. The first use of IFN- $\lambda$ in the clinic has started for hepatitis $\mathrm{C}$. The phase $1 \mathrm{~b}$ study has been conducted in patients with chronic genotype 1 hepatitis $\mathrm{C}$ virus infection ((HCV) [51]). Pegylated IFN- $\lambda 1$ in combination or not with ribavirin (RBV, which belongs to a class of antiviral medications called the nucleoside analogues) has been used in this study to assess the efficacy and the potential cytotoxicity. The study was performed in 3 parts. The first part evaluated the pegylated IFN$\lambda$ as single agent for relapsed patients after IFN- $\alpha$-based treatment. The second part concerned the combination of pegylated IFN- $\lambda$ and RBV in treatment-relapse patients. The third part evaluated pegylated IFN- $\lambda$ in combination with RBV in treatment-naïve patients. In addition, different doses (from 0.5 to $3 \mathrm{microg} / \mathrm{kg}$ ) of pegylated IFN- $\lambda$ were used. Fifty-six patients were enrolled. 24, 25, and 7 patients were used, respectively, for part 1 to 3 . The data showed an antiviral activity in all doses of pegylated IFN$\lambda$ tested. $29 \%$ of treatment-naïve patients achieved rapid antiviral response. As expected, due to the limited IFN$\lambda \mathrm{R} 1$ distribution, the treatment was well tolerated with few adverse effects. Minimal flu-like symptoms and limited hematologic suppression were reported. In summary, the authors concluded that weekly pegylated-IFN- $\lambda$ with or without daily RBV for 4 weeks is associated with a clear antiviral activity in patients with chronic HCV. However, this study lacks a direct comparison between IFN- $\lambda$ and IFN- $\alpha$ and the influence of viral and patient genotypes. Now it is well accepted that the response to IFN- $\alpha$ or the natural clearance of HCV infection is depending on singlenucleotide polymorphisms (SNPs), upstream of IFN- $\lambda 3$, which could be used as biomarkers to help determine the treatment outcome [52]. The first genome-wide association studies (GWAS) in HCV infection were reported by Ge et al.
They evaluated the treatment outcome in a group of 1671 patients of mixed ethnicity, receiving pegylated IFN- $\alpha$ and ribavirin. An association was discovered between sustained viral response (SVR) to treatment and a cluster of seven SNPs linked to the IFN- $\lambda 3$ gene, with the most significant SNP (rs12979860) demonstrating high statistical significance [53]. Many other studies have replicated these findings, demonstrating the high link between IFN- $\lambda 3$ and treatment outcome [54-61]. However the mechanisms explaining this link remain to be determined. It is not clear yet if this SNP is associated with a constitutive production of IFN- $\lambda$ that may play a role in HCV clearance and the success of IFN- $\alpha$ treatment. These results also suggest the therapeutic potential of the IFN- $\alpha$ and IFN- $\lambda$ combination therapy as demonstrated for the hepatocellular carcinoma (HCC) mouse model [62].

\section{Emergence of IFN- $\lambda$ as a New Antitumor Agent}

3.1. Characterization of the IFN- $\lambda$ System and Demonstration of Its Antitumor Activity in a Melanoma Model. Although they engage distinct receptors, IFN- $\alpha$ and IFN- $\lambda$ induce similar cell signaling (Figure 1). Since IFN- $\alpha$ is widely used in the clinic to treat cancer (Table 1), we have investigated the potential antitumor activity of IFN- $\lambda$ by using the mouse B16 melanoma model. We have chosen this cancer model because melanoma is a very aggressive cancer, and one of the therapeutic agents frequently used in the treatment of melanoma is IFN- $\alpha$. Significant improvements in relapsefree and overall survival, with postoperative adjuvant IFN$\alpha$ therapy, have been reported by large and randomized studies [63-65]. However, the beneficial effect of IFN- $\alpha$ was only obtained when the patients received high doses (20 MIU/m2 intravenously five times per week). Studies with low doses of IFN- $\alpha$ have not shown significant increase in overall survival $[66,67]$. Usually, the dose for optimal antitumor activity is higher than the maximally tolerated dose. This dose dilemma profoundly affects the acceptance of IFN- $\alpha$ treatment by both the clinicians and the patients. The adverse effects associated with high doses of IFN- $\alpha$ include myelosuppression and nervous system disorders. These effects often compromise the beneficial antitumor effect, with premature discontinuation of the treatment or the reduction of the dose of IFN- $\alpha$. Since virtually all the cells of the body respond to IFN- $\alpha$, it is not surprising that the patients develop numerous side effects. Making a dissection between the beneficial and harmful effects of IFN- $\alpha$ is a very challenging task, which requires more investigation of the interferon system. To investigate the antitumor effect of IFN- $\lambda$ in melanoma, we have used a gene therapy approach, consisting on the delivery of the IFN- $\lambda$ gene to tumor cells. Gene transfer into tumor cells is very useful approach to test the effectiveness of cytokines in animal cancer models. This approach does not require production and purification of the protein. The secretion of constant amounts of various cytokines by transduced tumor cells at the site of tumor growth could elicit more 
TABLE 1: Clinical indications of IFNs. IFN- $\alpha$ with different trade names is the most indicated in the clinic. IFN- $\beta$ is mostly indicated for the treatment of relapsing remitting multiple sclerosis. IFN- $\gamma$ is only indicated for the chronic granulomatous disease. IFN- $\lambda$, the new type of IFN, was tested for patients with chronic hepatitis C.

\begin{tabular}{ll}
\hline IFN type & Indications in the clinic \\
\hline & Hairy cell leukemia \\
& Multiple myeloma \\
& Chronic myeloid leukemia \\
& Follicular lymphoma \\
& Cutaneous T lymphoma \\
& Kaposi sarcoma \\
IFN- $\alpha$ & Melanoma \\
& Renal cell carcinoma \\
& Hepatocellular carcinoma \\
& Condyloma accuminata \\
& Hepatitis B \\
\hline IFN- $\beta$ & Hepatitis C \\
\hline IFN- $\gamma$ & Multiple sclerosis \\
\hline IFN- $\lambda$ & Chronic granulomatous disease \\
\hline
\end{tabular}

effective antitumor responses by acting directly on the tumor microenvironment. Another advantage of the cytokine gene transfer into tumor cells versus systemic administration is the potential of inducing the antitumor effect without eliciting the side effects associated with the systemic administration of high doses of cytokines.

To investigate the potential antitumoral role of IFN$\lambda$, we first evaluated the response of B16 melanoma cells to IFN- $\lambda$, by analyzing STAT1 activation and MHC class I antigen expression. In comparison with IFN- $\alpha$, we have found that IFN- $\lambda$ induces weak STAT1 phosphorylation but strong stimulation of MHC class I antigen expression, indicating a difference between IFN- $\alpha$ and IFN- $\lambda$ in the link intensity of cell signaling/biological activity. This result warrants further investigation in comparing the response to IFN- $\alpha$ and IFN- $\lambda$. By using gene transfer, we engineered B16 cells, which constitutively produced mIFN- $\lambda$ (B16.IFN$\lambda$ cells). In response to their secretion of IFN- $\lambda$, B16.IFN$\lambda$ cells exhibited constitutively high levels of MHC class I antigen expression. All the C57BL/6 syngeneic mice injected with parental B16 cells developed tumors. However, the constitutive production of mIFN- $\lambda$ by B16.IFN- $\lambda$ cells markedly affected tumorigenicity of the cells. B16.IFN- $\lambda$ cells were either rejected by the host or grew at a slower rate than control parental B16 cells. The antitumor effect of IFN- $\lambda$ was dose dependent. B16.IFN- $\lambda$ cells also inhibited the growth of parental B16 cells when both cell types were injected together [4]. We also used the engineered B16.IFN- $\lambda$ Res. cells, which, in addition to their constitutive IFN- $\lambda$ secretion, are completely resistant to IFN- $\lambda$, as demonstrated by the lack of IFN- $\lambda$-induced MHC class I antigen expression. Interestingly, similar to B16.IFN- $\lambda$ cells, we have found a reduction of the tumorigenicity of B16.IFN- $\lambda$ Res. cells, implying the involvement of host antitumor mechanisms induced by IFN- $\lambda[4]$.

Following our report on the characterization of the mouse IFN- $\lambda$ system and the potent antitumor activity of IFN- $\lambda$ in the B16 mouse melanoma model, independent groups confirmed the role of IFN $-\lambda$ as an antitumoral agent in melanoma and other tumor models. To demonstrate the antitumor activity of IFN- $\lambda$, Sato et al. [68] used the mouse melanoma B16F0 and B16F10 and the Colon 26 cell lines transfected with IFN- $\lambda 2$ cDNA. The IFN- $\lambda$-transduced B16F0 cells showed an increased activity of caspase $3 / 7$, an induction of p21 and a dephosphoryation of Rb, which triggered a cell cycle arrest and apoptosis. These events, obtained, in vitro, were apparently associated with a growth delay, observed in vivo after the injection of the B16F0 transduced with IFN- $\lambda$. A delay in tumor growth was also observed after the administration of the Colon 26 cells transduced with IFN- $\lambda$. By using the B16F10 cell line, which represents metastatic mouse melanoma cells, the authors showed that the overexpression of IFN- $\lambda$ significantly inhibited lung metastasis. In another study, to evaluate the antitumor activity of IFN- $\lambda$, Numasaki et al. [69] first transduced the mouse fibrosarcoma cells, MCA2005, with the retroviral vector PA317IL-28 (IFN- $\lambda 2$ ). Following the injection of the engineered tumor cells to mice, the authors observed a significant antitumor and antimetastatic effect in mice inoculated with the MCA2005IL-28 in comparison with those injected with the parental tumor cells.

3.2. Investigation of the Antitumor Activities of IFN- $\lambda$ in the BNL Mouse Model of Hepatocellular Carcinoma (HCC). HCC is the most prevalent type of liver cancer. It is the fifth most common solid tumor and the third leading cause of cancer-related death worldwide. It is also the second most lethal cancer with the five-year survival rate below 9\% [70-72]. Treatment options for HCC are limited mainly because of the inefficiency of existing anticancer chemotherapeutic drugs against HCC. Unfortunately, due to a lack of biomarkers and screening for HCC, most patients are diagnosed at advanced stages of the disease and do not meet strict selection criteria for potentially curative surgical tumor resection or orthotopic liver transplantation (OLT) [73-75]. In patients with unresectable HCC and preserved liver function, transarterial chemoembolization (TACE) has been shown to prolong survival. However TACE is rarely curative, and progression-free survival beyond 24 months is not frequent $[71,76]$. For patients with advanced disease, systemic chemotherapy is of limited benefit because of the resistance of HCC to existing anticancer drugs and the fact that about $50 \%$ of patients with HCC die secondary to liver failure from cirrhosis [77, 78]. HCC occurs most frequently in patients with cirrhosis as a result of chronic HBV (hepatitis B virus) and HCV (hepatitis C virus) infections, and alcohol abuse [72, 79]. Although the link between the cancer and the viral infection is not fully understood yet, there is some suggestion that viral infection interferes with signal transduction and consequently disrupts the normal, controlled growth of cells. 
Since IFN- $\alpha$ is used in the clinic for the treatment of chronic HCV and HBV infections, several studies evaluated the effect of IFN treatment on the incidence of HCC [72]. It was previously shown that the systemic administration of high doses and long-term IFN- $\alpha$ into nude mice bearing human HCC with high metastatic potential, following curative resection, inhibited tumor metastatis and recurrence [80]. The majority of clinical studies also concluded that IFN therapy, alone or in combination with ribavirin, decreased the incidence of HCC, particularly in patients with sustained virological response [81-84]. Therefore, IFN alone or, perhaps, in combination with other drugs can be used as a preventive therapy against the development of HCC in HCVand $\mathrm{HBV}$-infected patients. However, numerous side effects limit the overall tolerability of IFN- $\alpha$, particularly in patients with cirrhosis [85-87].

In the following part of this section, we describe our findings on the antitumor properties of IFN- $\lambda$ in the BNL mouse model of HCC. To evaluate the antitumor activities of both IFN- $\lambda$ and IFN- $\alpha$, we used a gene therapy approach as previously described [4]. We expressed IFN- $\lambda$ and IFN$\alpha$ genes under a strong constitutive promoter in BNL cells and selected stable cell lines, BNL-IFN- $\lambda$ and BNL-IFN- $\alpha$, constitutively expressing IFN- $\lambda$ and IFN- $\alpha$ [45]. Since the constitutive expression of IFN- $\lambda$ at the tumor site was found to affect the tumorigenicity of B16 melanoma cells in vivo [4], we examined whether similar effects of IFN- $\lambda$ would be displayed in the case of BNL hepatoma. Mice injected with BNL vector or parental BNL cells developed tumors in 4 to 6 weeks, whereas the tumor appearance for BNL-IFN- $\lambda$ cells was significantly delayed. Similar effects were obtained in mice inoculated with BNL-IFN- $\alpha$ cells. These experiments demonstrated that constitutive expression of IFNs at the tumor site resulted in the delay of tumor growth in vivo. Interestingly, we found that IFN- $\alpha$ and IFN- $\lambda$ exhibited similar antitumor activities [45].

\section{Potential Antitumor Mechanisms of IFN- $\alpha$ and IFN- $\lambda$}

4.1. Antitumor Mechanisms of IFN- $\alpha$. Despite the antiproliferative effects of IFN- $\alpha$, it seems that the direct effects on tumor cells may not be the major mechanism by which IFN$\alpha$ displays its antitumor activity. IFN- $\alpha$ can act indirectly on the tumor by inhibiting angiogenesis which is induced by the tumors and is required to promote their growth and metastasis [88]. In mice bearing human tumors, it was clearly demonstrated that the antitumor activity of IFN- $\alpha$ is associated with the inhibition of tumor angiogenesis in bladder carcinoma [89] and prostate cancer [90]. The involvement of the immune system in the antitumor mechanism of IFN$\alpha$ was strongly suggested by Gresser et al. [91, 92]. Early studies in tumor models have shown that an intact immune system was essential in IFN- $\alpha$-induced antitumor activities. The inhibition of Friend leukemia cells (FLC) by IFN- $\alpha$ in mice was shown to depend on the activation of host cells, such as NK cells and macrophages [92]. Both host humoral and cellular immune mechanisms were involved in the continued suppression of Friend erythroleukemia metastases after IFN- $\alpha$ treatment in mice [91]. In addition, effective adaptive immunotherapy was observed in a T-cell lymphoma model, after the injection of tumor-sensitized spleen cells and IFN- $\alpha$. By using antibodies against different immune cell populations, it has been shown that $\mathrm{CD}^{+} \mathrm{T}$ lymphocytes and $\mathrm{CD}^{+} \mathrm{T}$ lymphocytes were the major effectors in the antitumor activities induced by IFN- $\alpha[93,94]$.

4.2. Antitumor Mechanisms of IFN- $\lambda$. Although IFN- $\alpha$ and IFN- $\lambda$ signal quite similarly (Figure 1), the mechanisms underlying the antitumor activity of IFN- $\lambda$ may be qualitatively different from IFN- $\alpha$. As previously described, we initially investigated whether type III IFNs also possessed antitumor activities utilizing a gene therapy approach in the B16 melanoma model. Since secreted IFN- $\lambda$ did not affect the proliferation rate of B16 melanoma cells in vitro, studies in the B16 melanoma model suggested that IFN$\lambda$ acted through host mechanisms to elicit its antitumor activity [4]. However, we did not observe a significant longlasting immunity, implying that there may be a lack of effective adaptive immunity in the mice which rejected the tumor. On the other hand, we noticed a reduction in tumor vascularity in the presence of IFN- $\lambda$, suggesting a potential role of IFN- $\lambda$ in the tumor microenvironment [4]. Since we found that keratinocytes are highly sensitive to IFN- $\lambda$ and they are known to interact with melanocytes, the cells from which the melanoma originates, we suggested that IFN- $\lambda$ delivery to the tumor microenvironment may affect the function of the keratinocytes as well as other stroma cells thereby promoting inhibition of tumor growth [4]. NK cells, the major effectors of innate immunity, could also be recruited to the tumor microenvironment and help destroy the tumor cells. Two groups have reported that NK cells played a role in the antitumor mechanisms of IFN$\lambda$. Sato et al. [68] have described the involvement of NK cells in melanoma and colon cancer antitumor responses. They have shown that transient transduction of B16 cells with mouse IFN- $\lambda$ cDNA enhanced MHC class I and Fas expression, suppressed cell proliferation by inducing in-

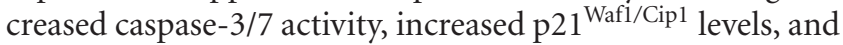
dephosphorylated $\mathrm{Rb}\left(\mathrm{Ser}^{780}\right)$ in vitro [68]. This meant that IFN- $\lambda$ was able to induce cell cycle arrest and apoptotic cell death in vitro. In addition, they have demonstrated that overexpression of IFN- $\lambda$ inhibited local and pulmonary metastatic tumor formation in vivo. Depletion of NK cells, by injecting an anti-asialo GM1 antibody before tumor cells injection, revealed that NK cells are important in this IFN$\lambda$-mediated tumor growth inhibition in vivo, suggesting that IFN- $\lambda$ activated the innate immune response [68]. Numasaki et al. [69] have also implicated NK cells, polymorphonuclear neutrophils, and $\mathrm{CD}^{+} \mathrm{T}$ cells in the antitumoral activity are induced by IFN- $\lambda$ in the MCA205 murine fibrosarcoma mouse model. Inoculation of MCA205-IFN- $\lambda$ cells into mice enhanced IFN- $\gamma$ production and cytotoxic T-cell activity in the spleen. The antitumor activity of IFN- $\lambda$ was partially dependent on IFN- $\gamma$. In addition, IFN- $\lambda$ increased the total number of splenic NK cells in severe combined immunodeficiency (SCID) mice, enhanced IL-12-induced IFN- $\gamma$ 
production in vivo, and expanded spleen cells in C57BL/6 mice. Furthermore, they reported that IL-12 augmented the IFN- $\lambda$-mediated antitumor activity in the presence or absence of IFN- $\gamma$. Based on their findings, they suggested that IFN- $\lambda$ is able to induce both innate and adaptive immune responses to suppress in vivo tumor growth [69].

Our recent study in the BNL hepatoma model also revealed that NK cells are implicated in the antitumor activity induced by IFN- $\lambda$ and probably more potently than IFN$\alpha$. However, in contrast to IFN- $\alpha$, we did not detect any response after in vitro treatment of $\mathrm{NK}$ cells by IFN- $\lambda$, suggesting that IFN- $\lambda$ may activate other cells, which then mediate NK cell activation [45]. There was also a marked NK cell infiltration in IFN- $\lambda$-producing tumors. In addition, IFN- $\lambda$ and, to a lesser extent, IFN- $\alpha$ enhanced immunocytotoxicity of splenocytes primed with irradiated BNL cells. Splenocyte cytotoxicity against BNL cells was dependent on IL-12 and IFN- $\gamma$ and mediated by dendritic cells. In contrast to $\mathrm{NK}$ cells, isolated from spleen, CD11c ${ }^{+}$and $\mathrm{mPDCA}^{+}$ dendritic cells responded directly to IFN- $\lambda$, suggesting that the effects of IFN- $\lambda$ on NK cells are mediated by other IFN- $\lambda$-responsive cells, such as DCs [45]. On the other hand, a significant decrease in $\mathrm{CD} 4^{+} \mathrm{CD} 25^{+}$Foxp $3^{+}$Tregs was observed in mice inoculated with BNL cells secreting IFN- $\alpha$, whereas the moderate decrease in Tregs observed in mice receiving BNL cells secreting IFN- $\lambda$ was not statistically significant [45]. Therefore, antitumor mechanisms activated by IFN- $\alpha$ and IFN- $\lambda$ may differ; IFN- $\lambda$ increased the number of NK cells at the tumor site whereas IFN- $\alpha$ had a stronger effect on Tregs in the BNL model.

These studies altogether suggest that although IFN- $\alpha$ and IFN- $\lambda$ signal quite similarly, differences exist in their biological potency, kinetics, and the sets of target cells sensitive to IFN- $\lambda$ and IFN- $\alpha$. Therefore, these two types of IFNs may have distinct physiological functions.

\section{IFN- $\lambda$ and IFN- $\alpha$ : Allies in Achieving Higher Antitumor Activities?}

Unlike IFN- $\alpha$, only a small subset of cells are sensitive to IFN- $\lambda$, implying that its potential clinical use may be associated with limited side effects. This presumption raises the question whether IFN- $\lambda$ could be an alternative to IFN- $\alpha$ in cancer therapy. However, despite the severe and numerous side effects inherent to IFN- $\alpha$ treatment [65], we believe that alternative treatment to IFN- $\alpha$ should be weighed first against the real benefits to patients in terms of overall survival and their tumor clearance. We have demonstrated in the BNL hepatoma model that the combination of IFN$\lambda$ and IFN- $\alpha$ could achieve a marked antitumor activity in comparison with the use of each IFN alone [62]. The benefits of the combination therapy of IFN- $\lambda$ and IFN- $\alpha$ have been demonstrated both by using a gene therapy approach and by direct administration of IFNs to the mice bearing the tumors. The mice injected with BNL cells secreting both IFN- $\lambda$ and IFN- $\alpha$ can completely reject the tumor, in contrast to the mice that only received the BNL-IFN- $\lambda$ cells or the BNLIFN- $\alpha$ cells. Furthermore, mice bearing established tumors and treated with exogenous IFN- $\lambda$ and IFN- $\alpha$ showed a drastic tumor repression. This effect was observed when the IFNs were delivered locally and even at low doses. Therefore, we believe that IFN- $\lambda$ is not simply acting like IFN- $\alpha$, with reduced side effects, but can be combined with IFN- $\alpha$ to achieve efficient antitumor activity. Combination of IFN- $\lambda$ with low doses of IFN- $\alpha$, which are subtherapeutic but less toxic [67], may improve IFN therapy and benefit cancer patients. Combinational therapy of IFN- $\lambda$ and IFN$\alpha$ may achieve ultimate antitumor activity by inducing complementary mechanisms directly on the tumor cells or by indirectly modulating the tumor microenvironment, thereby leading to the stimulation of the immune response against the tumor and the inhibition of tumor angiogenesis. By acting with different intensities on the same targets, IFN- $\lambda$ and IFN- $\alpha$ may generate a high level of synergy, leading to a potent antitumor activity.

\section{Conclusions}

Similarly to IFN- $\alpha$, IFN- $\lambda$ has been shown to play an important role in cancer and viral disease treatment. Although the two IFNs act through an identical signaling pathway in the cell, the pattern of their activity seems to be different in vivo, implying that IFN- $\lambda$ and IFN- $\alpha$ are not redundant cytokines. By acting on some targets with different intensities, we believe that IFN- $\lambda$ and IFN- $\alpha$ act in concert to better control tumor development in vivo. Therefore, to achieve better treatments for viral diseases or cancers, we believe that the development of a combination therapy rather than the use of each IFN alone will be more beneficial for the patients. The combination of IFNs with other cytokines, growth factors, or their antagonists could also be an important strategy for the improvement of the IFN therapy. Transforming growth factor-beta $(\mathrm{TGF} \beta)$ which plays a dual role in cancer, mediating tumor-suppresive activities at early stages and prooncogenic activities at later stages of tumor progression $[95,96]$, could represent one potentially important modulator or mediator of the IFN response. Understanding the potential crosstalks between IFN- $\alpha$, IFN$\lambda$ and other cytokines or growth factors, such as TGF $\beta$, could be rewarding and lead to new preclinical studies in animal models and new clinical trials resulting in better cancer treatments.

\section{Acknowledgment}

The authors thank Dr. Sergei Kotenko and Dr. Andrew De La Torre for their helpful discussions.

\section{References}

[1] R. P. Donnelly and S. V. Kotenko, "Interferon-lambda: a new addition to an old family," Journal of Interferon and Cytokine Research, vol. 30, no. 8, pp. 555-564, 2010.

[2] S. V. Kotenko, G. Gallagher, V. V. Baurin et al., "IFN- $\lambda$ s mediate antiviral protection through a distinct class II cytokine receptor complex," Nature Immunology, vol. 4, no. 1, pp. 69-77, 2003. 
[3] P. Sheppard, W. Kindsvogel, W. Xu et al., "IL-28, IL-29 and their class II cytokine receptor IL-28R," Nature Immunology, vol. 4, no. 1, pp. 63-68, 2003.

[4] A. Lasfar, A. Lewis-Antes, S. V. Smirnov et al., "Characterization of the mouse IFN- $\lambda$ ligand-receptor system: IFN- $\lambda \mathrm{s}$ exhibit antitumor activity against B16 melanoma," Cancer Research, vol. 66, no. 8, pp. 4468-4477, 2006.

[5] N. Ank, M. B. Iversen, C. Bartholdy et al., "An important role for type III interferon (IFN- $\lambda /$ IL-28) in TLR-induced antiviral activity," Journal of Immunology, vol. 180, no. 4, pp. 2474 2485, 2008.

[6] N. Ank, H. West, C. Bartholdy, K. Eriksson, A. R. Thomsen, and S. R. Paludan, "Lambda interferon (IFN- $\lambda$ ), a type III IFN, is induced by viruses and IFNs and displays potent antiviral activity against select virus infections in vivo," Journal of Virology, vol. 80, no. 9, pp. 4501-4509, 2006.

[7] D. Kugel, G. Kochs, K. Obojes et al., "Intranasal administration of alpha interferon reduces seasonal influenza A virus morbidity in ferrets," Journal of Virology, vol. 83, no. 8, pp. 3843-3851, 2009.

[8] M. Mordstein, G. Kochs, L. Dumoutier et al., "Interferon- $\lambda$ contributes to innate immunity of mice against influenza A virus but not against hepatotropic viruses," PLoS Pathogens, vol. 4, no. 9, Article ID e1000151, 2008.

[9] M. Li, X. Liu, Y. Zhou, and B. S. Shao, "Interferon- $\lambda$ s: the modulators of antivirus, antitumor, and immune responses," Journal of Leukocyte Biology, vol. 86, no. 1, pp. 23-32, 2009.

[10] G. Uzé and D. Monneron, "IL-28 and IL-29: newcomers to the interferon family," Biochimie, vol. 89, no. 6-7, pp. 729-734, 2007.

[11] S. H. Hong, O. Cho, K. Kim, H. J. Shin, S. V. Kotenko, and S. Park, "Effect of interferon-lambda on replication of hepatitis B virus in human hepatoma cells," Virus Research, vol. 126, no. 1-2, pp. 245-249, 2007.

[12] C. A. Lázaro, M. Chang, W. Tang et al., "Hepatitis C virus replication in transfected and serum-infected cultured human fetal hepatocytes," American Journal of Pathology, vol. 170, no. 2, pp. 478-489, 2007.

[13] T. Marcello, A. Grakoui, G. Barba-Spaeth et al., "Interferons $\alpha$ and $\lambda$ inhibit hepatitis $C$ virus replication with distinct signal transduction and gene regulation kinetics," Gastroenterology, vol. 131, no. 6, pp. 1887-1898, 2006.

[14] M. D. Robek, B. S. Boyd, and F. V. Chisari, "Lambda interferon inhibits hepatitis B and C virus replication," Journal of Virology, vol. 79, no. 6, pp. 3851-3854, 2005.

[15] W. Hou, X. Wang, L. Ye et al., "Lambda interferon inhibits human immunodeficiency virus type 1 infection of macrophages," Journal of Virology, vol. 83, no. 8, pp. 3837-3842, 2009.

[16] J. Li, S. Hu, L. Zhou et al., "Interferon lambda inhibits herpes simplex virus type I infection of human astrocytes and neurons," Glia, vol. 59, no. 1, pp. 58-67, 2011.

[17] A. Meager, K. Visvalingam, P. Dilger, D. Bryan, and M. Wadhwa, "Biological activity of interleukins-28 and -29: comparison with type I interferons," Cytokine, vol. 31, no. 2, pp. 109$118,2005$.

[18] S. G. Maher, F. Sheikh, A. J. Scarzello et al., "IFN $\alpha$ and IFN $\lambda$ differ in their antiproliferative effects and duration of JAK/STAT signaling activity," Cancer Biology and Therapy, vol. 7, no. 7, pp. 1109-1115, 2008.

[19] C. A. Biron, "Interferons $\alpha$ and $\beta$ as immune regulators-a new look," Immunity, vol. 14, no. 6, pp. 661-664, 2001.
[20] A. Le Bon and D. F. Tough, "Links between innate and adaptive immunity via type I interferon," Current Opinion in Immunology, vol. 14, no. 4, pp. 432-436, 2002.

[21] W. J. Jordan, J. Eskdale, M. Boniotto, M. Rodia, D. Kellner, and G. Gallagher, "Modulation of the human cytokine response by interferon lambda-1 (IFN- $\lambda 1 /$ IL-29)," Genes and Immunity, vol. 8, no. 1, pp. 13-20, 2007.

[22] N. J. Megjugorac, G. E. Gallagher, and G. Gallagher, "Modulation of human plasmacytoid DC function by IFN- $\lambda 1$ (IL29)," Journal of Leukocyte Biology, vol. 86, no. 6, pp. 1359-1363, 2009.

[23] J. Dai, N. J. Megjugorac, G. E. Gallagher, R. Y. L. Yu, and G. Gallagher, "IFN- $\lambda 1$ (IL-29) inhibits GATA3 expression and suppresses Th2 responses in human naive and memory $\mathrm{T}$ cells," Blood, vol. 113, no. 23, pp. 5829-5838, 2009.

[24] W. J. Jordan, J. Eskdale, S. Srinivas et al., "Human interferon lambda-1 (IFN- $\lambda 1 /$ IL-29) modulates the Th1/Th2 response," Genes and Immunity, vol. 8, no. 3, pp. 254-261, 2007.

[25] S. Srinivas, J. Dai, J. Eskdale, G. E. Gallagher, N. J. Megjugorac, and G. Gallagher, "Interferon- $\lambda 1$ (interleukin-29) preferentially down-regulates interleukin-13 over other T helper type 2 cytokine responses in vitro," Immunology, vol. 125, no. 4, pp. 492-502, 2008.

[26] D. M. A. Bullens, A. Decraene, E. Dilissen et al., “Type III IFN- $\lambda$ mRNA expression in sputum of adult and school-aged asthmatics," Clinical and Experimental Allergy, vol. 38, no. 9, pp. 1459-1467, 2008.

[27] S. L. Johnston, "Innate immunity in the pathogenesis of virusinduced asthma exacerbations," Proceedings of the American Thoracic Society, vol. 4, no. 3, pp. 267-270, 2007.

[28] E. M. Coccia, M. Severa, E. Giacomini et al., "Viral infection and toll-like receptor agonists induce a differential expression of type $\mathrm{I}$ and $\lambda$ interferons in humans plasmacytoid and monocyte-derived dendritic cells," European Journal of Immunology, vol. 34, no. 3, pp. 796-805, 2004.

[29] F. J. D. Mennechet and G. Uzé, "Interferon- $\lambda$-treated dendritic cells specifically induce proliferation of FOXP3-expressing suppressor T cells," Blood, vol. 107, no. 11, pp. 4417-4423, 2006.

[30] M. P. Morrow, P. Pankhong, D. J. Laddy et al., "Comparative ability of IL-12 and IL-28B to regulate Treg populations and enhance adaptive cellular immunity," Blood, vol. 113, no. 23, pp. 5868-5877, 2009.

[31] S. D. Der, A. Zhou, B. R. G. Williams, and R. H. Silverman, "Identification of genes differentially regulated by interferon $\alpha, \beta$, or $\gamma$ using oligonucleotide arrays," Proceedings of the National Academy of Sciences of the United States of America, vol. 95, no. 26, pp. 15623-15628, 1998.

[32] S. E. Doyle, H. Schreckhise, K. Khuu-Duong et al., "Interleukin-29 uses a type 1 interferon-like program to promote antiviral responses in human hepatocytes," Hepatology, vol. 44, no. 4, pp. 896-906, 2006.

[33] M. J. Clemens, "Interferons and apoptosis," Journal of Interferon and Cytokine Research, vol. 23, no. 6, pp. 277-292, 2003.

[34] D. V. Kalvakolanu, "The GRIMs: a new interface between cell death regulation and interferon/retinoid induced growth suppression," Cytokine and Growth Factor Reviews, vol. 15, no. 2-3, pp. 169-194, 2004.

[35] L. Dumoutier, A. Tounsi, T. Michiels, C. Sommereyns, S. V. Kotenko, and J. C. Renauld, "Role of the interleukin (IL)-28 receptor tyrosine residues for antiviral and antiproliferative activity of IL-29/interferon- $\lambda 1$. Similarities with type 1 interferon signaling," Journal of Biological Chemistry, vol. 279, no. 31, pp. 32269-32274, 2004. 
[36] S. Brand, F. Beigel, T. Olszak et al., "IL-28A and IL-29 mediate antiproliferative and antiviral signals in intestinal epithelial cells and murine CMV infection increases colonic IL-28A expression," American Journal of Physiology, vol. 289, no. 5, pp. G960-G968, 2005.

[37] K. Zitzmann, S. Brand, S. Baehs et al., "Novel interferon$\lambda s$ induce antiproliferative effects in neuroendocrine tumor cells," Biochemical and Biophysical Research Communications, vol. 344, no. 4, pp. 1334-1341, 2006.

[38] W. Li, A. Lewis-Antes, J. Huang, M. Balan, and S. V. Kotenko, "Regulation of apoptosis by type III interferons," Cell Proliferation, vol. 41, no. 6, pp. 960-979, 2008.

[39] A. J. Novak, D. M. Grote, S. C. Ziesmer, V. Rajkumar, S. E. Doyle, and S. M. Ansell, "A role for IFN- $\lambda 1$ in multiple myeloma B cell growth," Leukemia, vol. 22, no. 12, pp. 2240 2246, 2008.

[40] C. Sommereyns, S. Paul, P. Staeheli, and T. Michiels, "IFNlambda $($ IFN- $\lambda)$ is expressed in a tissue-dependent fashion and primarily acts on epithelial cells in vivo," PLoS Pathogens, vol. 4, no. 3, Article ID e1000017, 2008.

[41] J. Pott, T. Mahlakõiv, M. Mordstein et al., "IFN- $\lambda$ determines the intestinal epithelial antiviral host defense," Proceedings of the National Academy of Sciences of the United States of America, vol. 108, no. 19, pp. 7944-7949, 2011.

[42] N. A. Jewell, T. Cline, S. E. Mertz et al., "Lambda interferon is the predominant interferon induced by influenza A virus infection in vivo," Journal of Virology, vol. 84, no. 21, pp. 11515-11522, 2010.

[43] J. E. Pulverer, U. Rand, S. Lienenklaus et al., "Temporal and spatial resolution of type I and III interferon responses in vivo," Journal of Virology, vol. 84, no. 17, pp. 8626-8638, 2010.

[44] O. Koltsida, M. Hausding, A. Stavropoulos et al., "IL-28A (IFN- $\lambda 2$ ) modulates lung DC function to promote Th1 immune skewing and suppress allergic airway disease," EMBO Molecular Medicine, vol. 3, no. 6, pp. 348-361, 2011.

[45] W. Abushahba, M. Balan, I. Castaneda et al., "Antitumor activity of type I and type III interferons in BNL hepatoma model," Cancer Immunology, Immunotherapy, vol. 59, no. 7, pp. 1059-1071, 2010.

[46] K. Witte, G. Gruetz, H. D. Volk et al., "Despite IFN-receptor expression, blood immune cells, but not keratinocytes or melanocytes, have an impaired response to type III interferons: implications for therapeutic applications of these cytokines," Genes and Immunity, vol. 10, no. 8, pp. 702-714, 2009.

[47] K. Wolk, K. Witte, E. Witte et al., "Maturing dendritic cells are an important source of IL-29 and IL-20 that may cooperatively increase the innate immunity of keratinocytes," Journal of Leukocyte Biology, vol. 83, no. 5, pp. 1181-1193, 2008.

[48] C. Dellgren, H. H. Gad, O. J. Hamming, J. Melchjorsen, and R. Hartmann, "Human interferon- $\lambda 3$ is a potent member of the type III interferon family," Genes and Immunity, vol. 10, no. 2, pp. 125-131, 2009.

[49] C. Thomas, I. Moraga, D. Levin et al., "Structural linkage between ligand discrimination and receptor activation by type I interferons," Cell, vol. 146, no. 4, pp. 621-632, 2011.

[50] M. Mordstein, E. Neugebauer, V. Ditt et al., "Lambda interferon renders epithelial cells of the respiratory and gastrointestinal tracts resistant to viral infections," Journal of Virology, vol. 84, no. 11, pp. 5670-5677, 2010.

[51] A. J. Muir, M. L. Shiffman, A. Zaman et al., "Phase 1b study of pegylated interferon lambda 1 with or without ribavirin in patients with chronic genotype 1 hepatitis $\mathrm{C}$ virus infection," Hepatology, vol. 52, no. 3, pp. 822-832, 2010.
[52] C. Kelly, P. Klenerman, and E. Barnes, "Interferon lambdas: the next cytokine storm," Gut, vol. 60, no. 9, pp. 1284-1293, 2011.

[53] D. Ge, J. Fellay, A. J. Thompson et al., "Genetic variation in IL28B predicts hepatitis C treatment-induced viral clearance," Nature, vol. 461, no. 7262, pp. 399-401, 2009.

[54] D. Labie and H. Gilgenkrantz, "IL28 (interferon lambda3) gene polymorphisms and response to IFN-alpha treatment in patients infected with hepatitis virus C," Médecine Sciences, vol. 26, no. 3, pp. 225-226, 2010.

[55] A. Mangia, A. J. Thompson, R. Santoro et al., "An IL28B polymorphism determines treatment response of hepatitis $\mathrm{C}$ virus genotype 2 or 3 patients who do not achieve a rapid virologic response," Gastroenterology, vol. 139, no. 3, pp. 821e1, 2010.

[56] J. J. McCarthy, J. H. Li, A. Thompson et al., "Replicated association between an IL28B gene variant and a sustained response to pegylated interferon and ribavirin," Gastroenterology, vol. 138, no. 7, pp. 2307-2314, 2010.

[57] M. A. Montes-Cano, J. R. García-Lozano, C. Abad-Molina et al., "Interleukin-28B genetic variants and hepatitis virus infection by different viral genotypes," Hepatology, vol. 52, no. 1, pp. 33-37, 2010.

[58] T. L. Mosbruger, P. Duggal, J. J. Goedert et al., "Large-scale candidate gene analysis of spontaneous clearance of hepatitis C virus," Journal of Infectious Diseases, vol. 201, no. 9, pp. 1371-1380, 2010.

[59] A. Rauch, Z. Kutalik, P. Descombes et al., "Genetic variation in IL28B is associated with chronic hepatitis C and treatment failure: a genome-wide association study," Gastroenterology, vol. 138, no. 4, pp. 1338-1345, 2010.

[60] V. Suppiah, M. Moldovan, G. Ahlenstiel et al., "IL28B is associated with response to chronic hepatitis $\mathrm{C}$ interferon- $\alpha$ and ribavirin therapy," Nature Genetics, vol. 41, no. 10, pp. 1100-1104, 2009.

[61] Y. Tanaka, N. Nishida, M. Sugiyama et al., "Genome-wide association of IL28B with response to pegylated interferon- $\alpha$ and ribavirin therapy for chronic hepatitis C," Nature Genetics, vol. 41, no. 10, pp. 1105-1109, 2009.

[62] A. Lasfar, W. Abushahba, A. de la Torre, I. Castaneda, S. V. Kotenko, and K. Reuhl, "IFN therapy in TIB75 HCC model: combination of IFN-lambda and IFN-alpha induces complete remission," Hepathology, vol. 48, no. 4, supplement, \#191, 2008.

[63] J. M. Kirkwood, J. Ibrahim, D. H. Lawson et al., "High-dose interferon alfa-2b does not diminish antibody response to GM2 vaccination in patients with resected melanoma: results of the multicenter eastern cooperative oncology group phase II trial E2696," Journal of Clinical Oncology, vol. 19, no. 5, pp. 1430-1436, 2001.

[64] J. M. Kirkwood, M. H. Strawderman, M. S. Ernstoff, T. J. Smith, E. C. Borden, and R. H. Blum, "Interferon alfa-2b adjuvant therapy of high-risk resected cutaneous melanoma: the Eastern Cooperative Oncology Group trial EST 1684," Journal of Clinical Oncology, vol. 14, no. 1, pp. 7-17, 1996.

[65] S. Moschos, S. Varanasi, and J. M. Kirkwood, "Interferons in the treatment of solid tumors," Cancer Treatment and Research, vol. 126, pp. 207-241, 2005.

[66] N. Cascinelli, F. Belli, R. M. MacKie, M. Santinami, R. Bufalino, and A. Morabito, "Effect of long-term adjuvant therapy with interferon alpha-2a in patients with regional node metastases from cutaneous melanoma: a randomised trial," Lancet, vol. 358, no. 9285, pp. 866-869, 2001. 
[67] U. R. Kleeberg, S. Suciu, E. B. Bröcker et al., "Final results of the EORTC 18871/DKG 80-1 randomised phase III trial: rIFN$\alpha 2 \mathrm{~b}$ versus rIFN- $\gamma$ versus ISCADOR $\mathrm{M}$ versus observation after surgery in melanoma patients with either high-risk primary (thickness $>3 \mathrm{~mm}$ ) or regional lymph node metastasis," European Journal of Cancer, vol. 40, no. 3, pp. 390-402, 2004.

[68] A. Sato, M. Ohtsuki, M. Hata, E. Kobayashi, and T. Murakami, "Antitumor activity of IFN- $\lambda$ in murine tumor models," Journal of Immunology, vol. 176, no. 12, pp. 7686-7694, 2006.

[69] M. Numasaki, M. Tagawa, F. Iwata et al., "IL-28 elicits antitumor responses against murine fibrosarcoma," Journal of Immunology, vol. 178, no. 8, pp. 5086-5098, 2007.

[70] P. A. Farazi and R. A. DePinho, "Hepatocellular carcinoma pathogenesis: from genes to environment," Nature Reviews Cancer, vol. 6, no. 9, pp. 674-687, 2006.

[71] W. Y. Lau and E. C. H. Lai, "Hepatocellular carcinoma: current management and recent advances," Hepatobiliary and Pancreatic Diseases International, vol. 7, no. 3, pp. 237-257, 2008.

[72] M. Sherman, "Hepatocellular carcinoma: epidemiology, risk factors, and screening," Seminars in Liver Disease, vol. 25, no. 2, pp. 143-154, 2005.

[73] V. Mazzaferro, Y. S. Chun, R. T. P. Poon et al., "Liver transplantation for hepatocellular carcinoma," Annals of Surgical Oncology, vol. 15, no. 4, pp. 1001-1007, 2008.

[74] V. Mazzaferro, J. M. Llovet, R. Miceli et al., "Predicting survival after liver transplantation in patients with hepatocellular carcinoma beyond the Milan criteria: a retrospective, exploratory analysis," The Lancet Oncology, vol. 10, no. 1, pp. 35-43, 2009.

[75] A. Taketomi, Y. Soejima, T. Yoshizumi, H. Uchiyama, Y. I. Yamashita, and Y. Maehara, "Liver transplantation for hepatocellular carcinoma," Journal of Hepato-Biliary-Pancreatic Surgery, vol. 15, no. 2, pp. 124-130, 2008.

[76] C. S. Georgiades, K. Hong, and J. F. Geschwind, "Radiofrequency ablation and chemoembolization for hepatocellular carcinoma," Cancer Journal, vol. 14, no. 2, pp. 117-122, 2008.

[77] A. M. Di Bisceglie, R. L. Carithers, and G. J. Gores, "Hepatocellular carcinoma," Hepatology, vol. 28, no. 4 I, pp. 1161-1165, 1998.

[78] H. Nagai and Y. Sumino, "Therapeutic strategy of advanced hepatocellular carcinoma by using combined intra-arterial chemotherapy," Recent Patents on Anti-Cancer Drug Discovery, vol. 3, no. 3, pp. 220-226, 2008.

[79] H. B. El-Serag, "Hepatocellular carcinoma: an epidemiologic view," Journal of Clinical Gastroenterology, vol. 35, no. 5, pp. S72-S78, 2002.

[80] L. Wang, W. Z. Wu, H. C. Sun et al., "Mechanism of interferon alpha on inhibition of metastasis and angiogenesis of hepatocellular carcinoma after curative resection in nude mice," Journal of Gastrointestinal Surgery, vol. 7, no. 5, pp. 587-594, 2003.

[81] G. Fattovich, G. Giustina, J. Sanchez-Tapias et al., "Delayed clearance of serum HBsAG in compensated cirrhosis B: relation to interferon alpha therapy and disease prognosis," The American Journal of Gastroenterology, vol. 93, no. 6, pp. 896-900, 1998.

[82] S. M. Lin, M. L. Yu, C. M. Lee et al., "Interferon therapy in $\mathrm{HBeAg}$ positive chronic hepatitis reduces progression to cirrhosis and hepatocellular carcinoma," Journal of Hepatology, vol. 46, no. 1, pp. 45-52, 2007.

[83] M. Omata, H. Yoshida, and Y. Shiratori, "Prevention of hepatocellular carcinoma and its recurrence in chronic hepatitis $\mathrm{C}$ patients by interferon therapy," Clinical Gastroenterology and Hepatology, vol. 3, no. 2, pp. S141-S143, 2005.
[84] M. L. Yu, S. M. Lin, W. L. Chuang et al., "A sustained virological response to interferon or interferon/ribavirin reduces hepatocellular carcinoma and improves survival in chronic hepatitis C: a nationwide, multicentre study in Taiwan," Antiviral Therapy, vol. 11, no. 8, pp. 985-994, 2006.

[85] J. M. Llovet, M. Sala, L. Castells et al., "Randomized controlled trial of interferon treatment for advanced hepatocellular carcinoma," Hepatology, vol. 31, no. 1, pp. 54-58, 2000.

[86] C. M. Lo, C. L. Liu, S. C. Chan et al., "A randomized, controlled trial of postoperative adjuvant interferon therapy after resection of hepatocellular carcinoma," Annals of Surgery, vol. 245, no. 6, pp. 831-842, 2007.

[87] K. Ueshima, M. Kudo, T. Nagai et al., "Combination therapy with S-1 and pegylated interferon alpha for advanced hepatocellular carcinoma," Oncology, vol. 75, no. 1, pp. 106-113, 2008.

[88] Y. A. Sidky and E. C. Borden, "Inhibition of angiogenesis by interfersons: effects on tumor- and lymphocyte-induced vascular responses," Cancer Research, vol. 47, no. 19, pp. 51555161, 1987.

[89] C. P. N. Dinney, D. R. Bielenberg, P. Perrotte et al., "Inhibition of basic fibroblast growth factor expression, angiogenesis, and growth of human bladder carcinoma in mice by systemic interferon- $\alpha$ administration," Cancer Research, vol. 58, no. 4, pp. 808-814, 1998.

[90] Y. Dong, W. M. Rohn, and E. N. Benveniste, "IFN- $\gamma$ regulation of the type IV class II transactivator promoter in astrocytes," Journal of Immunology, vol. 162, no. 8, pp. 4731-4739, 1999.

[91] I. Gresser, "Antitumour effects of interferons: past, present and future," British Journal of Haematology, Supplement, vol. 79, no. 1, pp. 1-5, 1991.

[92] I. Gresser, T. Kaido, C. Maury, D. Woodrow, J. Moss, and F. Belardelli, "Interaction of IFN $\alpha / \beta$ with host cells essential to the early inhibition of friend erythroleukemia visceral metastases in mice," International Journal of Cancer, vol. 57, no. 4, pp. 604-611, 1994.

[93] T. Kaido, C. Maury, V. Schirrmacher, and I. Gresser, "Successful immunotherapy of the highly metastatic murine ESb lymphoma with sensitized CD8 ${ }^{+}$T cells and IFN- $\alpha / \beta$," International Journal of Cancer, vol. 57, no. 4, pp. 538-543, 1994.

[94] T. J. Kaido, C. Maury, and I. Gresser, "Host CD4+ T lymphocytes are required for the synergistic action of interferon $\alpha / \beta$ and adoptively transferred immune cells in the inhibition of visceral ESb metastases," Cancer Research, vol. 55, no. 24, pp. 6133-6139, 1995.

[95] D. Javelaud, V. I. Alexaki, and A. Mauviel, "Transforming growth factor- $\beta$ in cutaneous melanoma," Pigment Cell \& Melanoma Research, vol. 21, no. 2, pp. 123-132, 2008.

[96] A. Lasfar and K. A. Cohen-Solal, "Resistance to transforming growth factor $\beta$-mediated tumor suppression in melanoma: are multiple mechanisms in place?" Carcinogenesis, vol. 31, no. 10, pp. 1710-1717, 2010. 


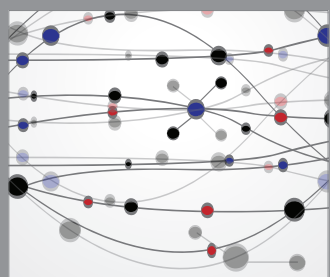

The Scientific World Journal
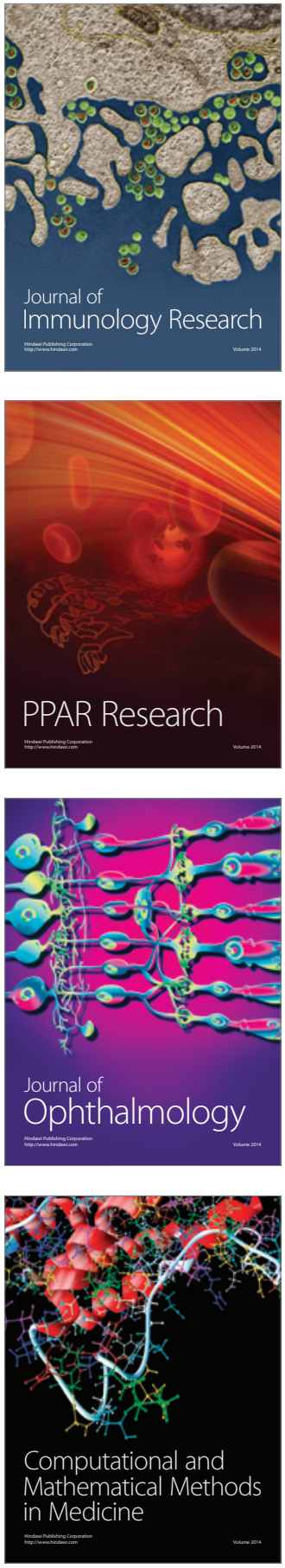

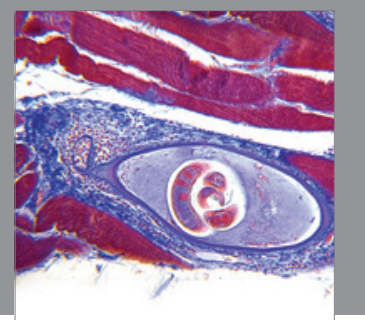

Gastroenterology

Research and Practice
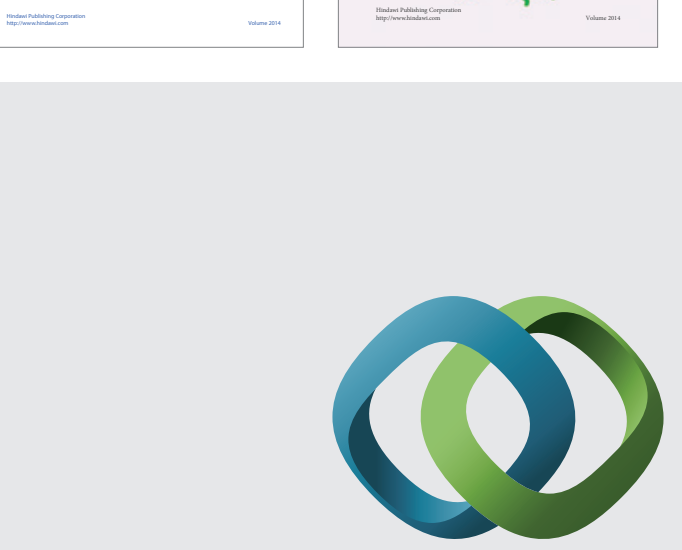

\section{Hindawi}

Submit your manuscripts at

http://www.hindawi.com
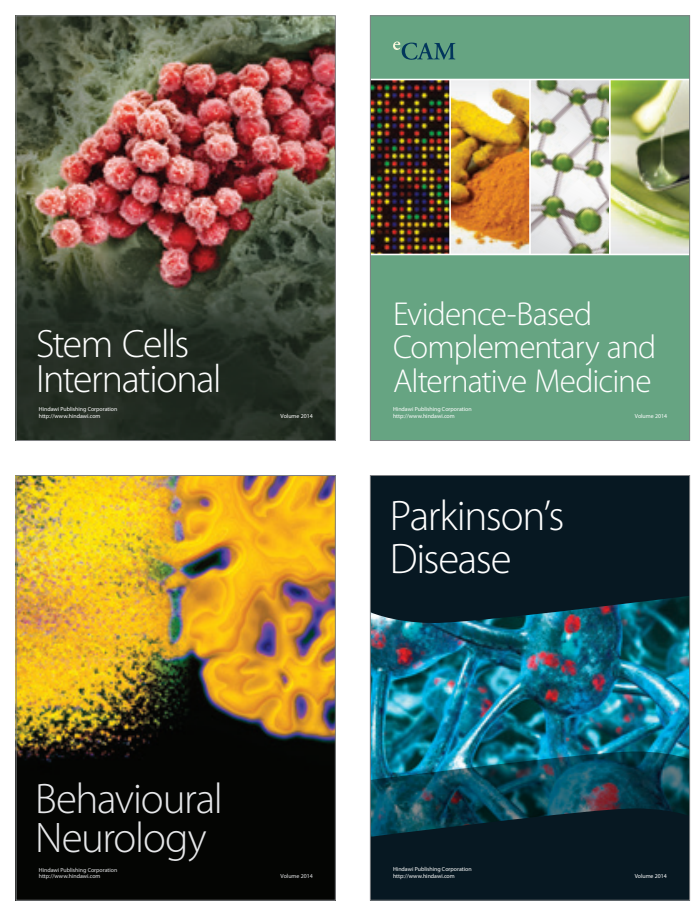

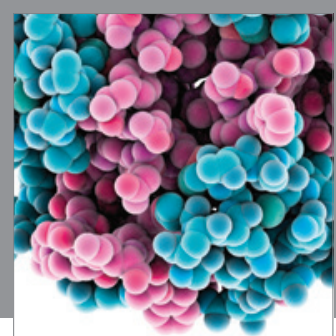

Journal of
Diabetes Research

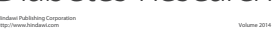

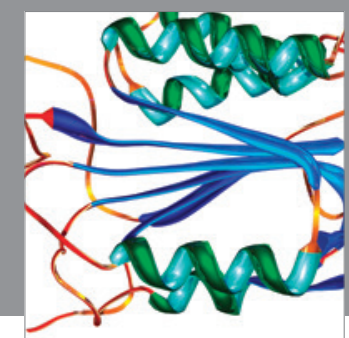

Disease Markers
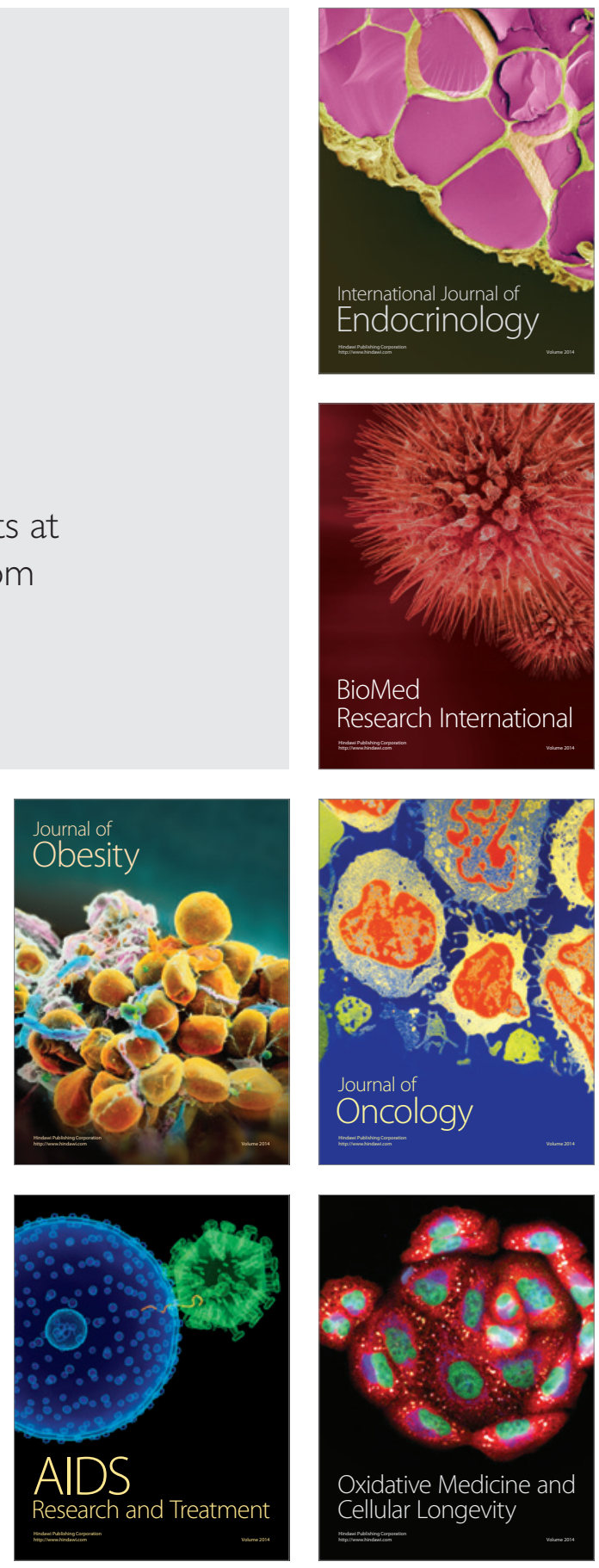